\title{
Relações de opressão- exploração da modernidade colonial: notas sobre cidadania trans e emancipação
}

\begin{abstract}
Oppression-exploitation relationships in colonial modernity: notes on trans citizenship and emancipation
\end{abstract}

\author{
Silvana Marinho*
}

\begin{abstract}
Resumo - A partir de uma abordagem feminista marxista, o presente artigo propõe-se a refletir sobre a cidadania trans, situando as determinações dos limites da cidadania no seio de uma sociabilidade capitalista, (cis)heteropatriarcal e racista, própria da modernidade colonial, bem como considerando que pessoas trans também são sujeitos políticos revolucionários e disputam os significados e as práticas do que é ser cidadão/ã. Na produção teórica da tradição marxista e nos debates políticos, a apreensão da exploração-opressão como unidade ainda ocupa lugar periférico. Portanto, o texto traz elementos para o debate acerca da emancipação política e humana denunciando o falso dilema entre lutas gerais e lutas específicas.

Palavras-chave: pessoas trans; relações de opressão-exploração; modernidade colonial; cidadania; emancipação.
\end{abstract}

\begin{abstract}
From a feminist Marxist approach, this article reflects on trans citizenship, situating the determinations of the limits of citizenship within a racist, (cis)heteropatriarchal capitalist sociability, characteristic of colonial modernity. It also proposes that transgender people are revolutionary political subjects, and dispute the meanings and practices of being a citizen. In the theoretical production of Marxist tradition and political debates, apprehending exploration-oppression as a unit still occupies a peripheral place. Therefore, the article brings elements to the debate on the political and human emancipation, denouncing the false dilemma between general and specific struggles.

Keywords: transgender; oppression-exploitation relationships; colonial modernity; citizenship; emancipation.
\end{abstract}

\footnotetext{
*Assistente Social. Doutoranda em Serviço Social no PPGSS/UFRJ. Mestre em Serviço Social pelo PPGSS/UERJ. Especialista em Políticas Públicas e Cultura de Direitos (NEPP-DH/UFRJ) e em Gênero e Sexualidade (IMS/UERJ). Pesquisadora do Laboratório Interdisciplinar de Estudos e Intervenção em Políticas Públicas de Gênero (LIEIG/NEPP-DHUFRJ). É membra da Comissão Temática Gênero, Etnia e Diversidade Sexual (GEDS) do CRESS/RJ e conselheira suplente do Conselho Estadual LGBTI do Rio de Janeiro. Possui apoio à pesquisa pela CAPES, sob o processo n⿳0 88882.424620/ 2019-01. E-mail:marinho.silvana@gmail.com. ORCID: https://orcid.org/0000-0003-3110-3902.
} 


\section{Introdução}

Pessoas trans são aquelas que vivenciam diferentes pertencimentos de gênero não normativo, autodenominando-se pessoas travesti, transgênero, homem transexual e mulher transexual. O termo trans é aqui utilizado relativamente à própria forma êmica com a qual tem se expressado no movimento social e na academia, auxiliando a aglutinar as vivências de pessoas que escapam à cisgeneridade. Rodovalho (2017), ao refletir sobre o termo cis pelo termo trans, demonstra que não é possível imaginar a utilização de um desses termos sem nos referirmos prontamente ao outro. Etimologicamente, se de um lado o "trans" significa além de ou aquilo que cruza, que atravessa; de outro, o "cis" vem em sua oposição, significando da parte de cá, deste lado; logo, aquilo que permanece num mesmo lado. A partir desse ponto e, como travesti, Rodovalho (2017, p. 365) afirma que "o discurso médico, ao nomear como 'trans' a nossa maneira peculiar de existir, de reivindicar existência, automaticamente nomeou a outra maneira, a sua maneira, não-trans, como 'cis' ". Ademais, cabe ressaltar que essas existências trans são anteriores à nossa sociedade contemporânea. O que é contemporâneo é a presença do termo trans como categoria política e como conceito, que se relaciona com a politização desses sujeitos nas últimas décadas e com o avanço dos estudos sobre gênero e sexualidade, a despeito de ter uma história edificada no discurso médico'.

A memória da luta trans, conquanto tenha se singularizado em termos de reivindicação de direitos, coaduna-se à história da luta LGBTQIA+, que se manifesta hoje de forma mais ampla como resposta às discriminações em razão do gênero e da sexualidade, em prol da conquista da igualdade de direitos à livre expressão sexual e de gênero.

Ressalta-se que o termo LGBT (lésbicas, gays, bissexuais, travestis e transexuais) veio sendo, a partir dos anos 2000, a expressão mais utilizada no campo do ativismo da diversidade sexual e de gênero a partir das conferências nacionais LGBT (I, II e III), realizadas desde 2008. Entretanto, como se trata de uma expressão em constante disputa, esse ativismo, ainda mais recentemente, vem reivindicando a sigla LGBTQIA+, de modo a buscar contemplar outras vivências de gênero e sexualidade, acrescentando-se o "Q" de queer, o "I" de intersexuais, o " $\mathrm{A}$ " de assexuais e o " + " para outras múltiplas formas de expressão de gênero e de orientação sexual, bem como para aquelas pessoas que não se identificam com quaisquer dos binarismos de gênero.

A formulação de políticas públicas LGBTQIA+ veio se desenhando, mais formalmente, desde meados dos anos 2000 com a criação do Programa Federal Brasil sem Homofobia (BsH). Entretanto, o cenário atual, com o

${ }^{1}$ Cabe citar Pierre-Henri Castel (2001), Berenice Bento (2006) e Mário Felipe de Carvalho (2011) como leituras relevantes para a contextualização da edificação das identidades trans pelos discursos e saberes do campo biomédico, que foram sintetizadas em Marinho (2017). 
governo autoritário e de tendência protofascista de Bolsonaro, tem sido de derrocada de conquistas históricas, desde normativas legais às ossaturas de políticas.

Apesar de o campo da diversidade sexual e de gênero abarcar as identidades LGBTQIA+, a identidade de gênero vem se configurar como um elemento que reitera a distinção identitária entre travestis e transexuais, de um lado, e gays, lésbicas e bissexuais, de outro (CARVALHO, 2011). Destarte, embora se reconheça a inter-relação existente entre sexualidade e gênero, uma vez que os padrões de gênero, suas hierarquias e sua base ideológica patriarcal-capitalista incidem sobre a sexualidade, o assunto diversidade de gênero não deve ser adunado ao assunto da diversidade sexual, pois cada qual expressa vivências e pautas políticas diferentes, nos chamando a atenção para a importância dessa distinção a fim de compreendermos a problemática de fundo que se relaciona com as discriminações sentidas pelas pessoas trans (MARINHO, 2018).

Trata-se de um segmento da classe trabalhadora que, frequentemente, tem suas vidas marcadas pelas violações de direitos de cidadania, como a negação de acesso ao trabalho, à educação, à saúde, à justiça e à assistência social. Isso é a expressão do abismo, próprio da chamada sociedade moderna, entre os direitos formais e as condições concretas de existência.

Sabe-se que a tradição marxista é crítica da democracia burguesa formal. São várias as teses da incompatibilidade entre democracia e capitalismo, como em Ellen Wood (2011) e em Carlos Nelson Coutinho (1997), para quem a construção dos direitos democráticos que caracteriza a modernidade termina por se chocar com a lógica do capital, evidenciando a contradição entre cidadania e classe social. Concordantemente com Coutinho (1997) e Wood (2011), a universalização da cidadania é incompatível com a existência de uma sociedade de classes. Contudo, há que se destacar que não apenas a categoria classe social obstaculiza a universalização da cidadania, mas a simbiose entre capitalismo, patriarcado e racismo torna a cidadania plena irrealizável.

Ao analisar a afirmação de Wood (2011, p. 172) de que "na democracia capitalista moderna a desigualdade e a exploração socioeconômica coexistem com a liberdade e a igualdade cívicas", é possível dizer que tal asserção aparentemente nos faz concordar com a autora. No entanto, ela carece de profundidade quando consideramos a complexidade das novas determinações dos antagonismos advindos da modernidade.

No que se refere às questões trans, as igualdades cívicas e as liberdades nem mesmo se encontram no plano formal, uma vez que, antes, a pessoa trans mereceria o reconhecimento jurídico-político. Este não tem sido o caso. Nesse sentido, as pessoas trans, "antes de reivindicar os direitos relacionados à sua pessoa, estão lutando para serem reconhecidas como pessoas", nos termos assinalados por Flavia Teixeira (2009, p. 32). Uma 


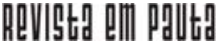

\} RELAÇÃO DE OPRESSÃO - MARINHO, S. \}

DOI: $10.12957 /$ rep.2021.56075

questão central para ilustrar o que se problematiza é o não reconhecimento do nome social nos diversos espaços, equipamentos sociais e de saúde, órgãos públicos e privados, nas unidades de ensino e no trabalho. O direito ao nome é passaporte para todos os outros direitos, porque, em sentido lato, é o direito de existir.

Por conseguinte, na falta de uma lei de identidade de gênero no Brasil $^{2}$ que regulamente e facilite o direito à expressão de gênero, a população trans - que tem acessado a retificação do seu registro civil judicialmente - vem recentemente reivindicando esse direito, não sem dificuldades, no Registro Civil das Pessoas Naturais em face de uma decisão atual de março de 2018, do Supremo Tribunal Federal (STF), que autorizou a alteração de nome e sexo para pessoas transexuais, travestis e transgêneros diretamente em cartório. Uma decisão muito comemorada pela comunidade trans, mas que ainda demonstra a dificuldade da devida atenção do poder público para com a cidadania trans.

Existe um fosso entre a formulação e a implementação de políticas públicas LGBTQIA+ no território nacional, visto que essas políticas não escapam à lógica que orienta as políticas sociais brasileiras. Elas estão assentadas no solo de um Estado de capitalismo periférico submetido às exigências do ideário neoliberal de países centrais, que tanto as fragmenta e as desfinanceiriza. Ademais, o vácuo legal no Brasil no que diz respeito ao assunto identidade de gênero e às conquistas logradas (a conta-gotas) mostra-se, especialmente, pelo fato de o parlamento ser composto por uma elite racista, machista e conservadora, como Berenice Bento (2014) assinala.

Em vista do exposto, este artigo reflete sobre identidade de gênero e cidadania à luz do materialismo histórico dialético e do feminismo marxista e decolonial, compreendendo que este tema requer, de um lado, identificar as determinações sociais dos limites da cidadania trans no seio de uma sociabilidade capitalista-(cis)heteropatriarcal-racista, própria da modernidade colonial, e, de outro, considerar que pessoas trans também são sujeitos políticos revolucionários e disputam os significados e as práticas do que é ser cidadão/ã.

Busca-se, ainda, trazer alguns elementos de análise que possam contribuir para imprimir sentido de classe aos processos de luta no campo da diversidade de gênero, bem como consciência de gênero e raça nas lutas trabalhistas, particularmente diante dos desafios atuais da cena contemporânea brasileira, fortalecendo uma unidade das lutas sociais.

As forças sociais progressistas em presença no cenário brasileiro, em tempos de crise do capital, neoconservadorismo, obscurantismo, autoritarismo, desmonte de direitos e ultraneoliberalismo, expressam-se como lutas plurais que, ao contrário da fragmentação, têm potencial emancipa-

2 Já existe uma iniciativa neste sentido, que é o Projeto de Lei João Nery (n 5002/2013), de autoria de Jean Wyllys (PSOL/RJ) e Erika Kokay (PT/DF), que, em 2019 foi novamente arquivado ao ir para a Mesa Diretora da Câmara dos Deputados, e, no presente momento, encontra-se na Coordenação de Comissões Permanentes (CCP). 
tório, pois são uma unidade do diverso, animando, assim, uma caminhada em direção a uma luta da classe trabalhadora verdadeiramente comprometida com a emancipação humana: uma luta anticapitalista, anticolonial, antirracista e anti-(cis)heteropatriarcal.

Tal discussão encoraja uma reflexão acerca da emancipação política e humana numa perspectiva marxista, que, não raras vezes, acaba por incorrer no falso dilema presente no campo das forças de esquerda: os embates teórico-políticos entre lutas gerais e lutas específicas. Ademais, na produção teórica da tradição marxista e nos debates políticos, a apreensão da exploração-opressão como unidade ainda ocupa um lugar periférico. Destarte, o esforço reflexivo deste artigo é o de reconhecer a indissociabilidade entre as determinações de gênero, raça/etnia e classe, porque são contradições que constituem a realidade concreta.

\section{Feminismo e marxismo: lentes necessárias para a leitura dos processos de opressão-exploração da modernidade colonial}

O método materialista histórico-dialético, por ser um método pautado na perspectiva da historicidade, das contradições e da totalidade, apresenta-se como um importante legado analítico para a interpretação das novas realidades do processo histórico. A ontologia no pensamento marxiano e os elementos metodológicos de sua teoria social permitem compreender as determinações do sistema opressão-exploração na totalidade das relações sociais.

Nesse sentido, com o método marxista é possível alcançar o concreto pensado. De acordo com Kosik (1976), para se alcançar a totalidade concreta faz-se premente a destruição da pseudoconcreticidade (na qual o fenômeno é confundido com a essência do real), desnaturalizando-se o que a ideologia burguesa insiste em afirmar como natural. Como a realidade não é autoevidente, para a investigação de um objeto faz-se necessário conhecer o concreto para além de sua aparência. Isso requer uma investigação dialética, que, segundo Kosik (1976), desnuda a essência dos fenômenos, sua constituição e suas interdependências, e expressa, também, uma práxis revolucionária.

[...] a destruição da pseudoconcreticidade como método dialéticocrítico, graças à qual o pensamento dissolve as criações fetichizados do mundo reificado e ideal, para alcançar sua realidade, é apenas o outro lado da dialética, como método revolucionário de transformação da realidade. Para que o mundo possa ser explicado 'criticamente', cumpre que a explicação mesma se coloque no terreno da práxis revolucionária. (KOSIK, 1976, p. 18 - Grifos do autor). 
A teoria social crítica marxiana tem, assim, uma dimensão teórica e política. Ela é a filosofia da práxis, é pensamento e ação. Na teoria gramsciana, filosofia, história e política são indissociáveis, pois filosofar é essencialmente histórico e coletivo, e não uma elaboração individual; é também político, pois os sujeitos históricos ao filosofar estão em relação ativa de modificação do ambiente cultural (GRAMSCI, 1978).

Considerando seu cariz teórico (a reprodução ideal do movimento real constitutivo do ser social na ordem burguesa), a teoria social facilita a compreensão da estrutura e da dinâmica da sociedade burguesa a partir de uma base material e concreta, qual seja: as relações sociais de produção e reprodução da vida social, isto é, as relações de classe, produzidas pelo modo capitalista que têm como elemento central o trabalho.

A partir da ontologia marxiana do ser social, compreende-se que o trabalho se configura como fonte de satisfação das necessidades materiais de sobrevivência, para o desenvolvimento da sociabilidade humana e como possibilidade história. Ele é ontocriativo, pois "é um processo que permeia todo o ser [humano] e constitui a sua especificidade" (KOSIK, 1976, p. 180). O que diferencia o ser humano dos demais animais é justamente a capacidade teleológica de produzir seus próprios meios de vida. Na esteira da concepção materialista histórica, homens e mulheres são sujeitos sóciohistóricos. Tratar do materialismo em Marx é tratar, portanto, necessariamente da história, produto e processo da ação humana, justamente porque a história tem uma base material. Assim:

[...] o primeiro pressuposto de toda a existência humana e, também, portanto, de toda a história, a saber, o pressuposto de que os homens [e as mulheres] têm de estar em condições de viver para poder 'fazer história'. [...] O primeiro ato histórico é, pois, a produção dos meios para a satisfação dessas necessidades, a produção da própria vida material, [...] uma condição fundamental do toda a história [...]. (MARX; ENGELS, 2007, p. 32-33).

Com as mudanças históricas nas formas de produzir e reproduzir a vida em sociedade, o desenvolvimento das forças produtivas chegou ao contexto de uma sociedade capitalista, com uma economia mundial. É na sociabilidade burguesa que o trabalho concreto, enquanto categoria ontológica para satisfação das necessidades básicas humanas, fica subsumido ao capital. Assume, então, a forma de trabalho abstrato ao adquirir outras determinações sociais e históricas, como o trabalho produtivo, que gera mais-valia e valoriza o capital; o trabalho assalariado, submetido às leis que regulam o preço do trabalho na sociedade moderna; e o trabalho alienado, fazendo do trabalhador um ser estranho ao que produz (MARX, 2004).

É, por consequência, na sociabilidade burguesa, com a contradição capital e trabalho, bem como a apropriação da propriedade privada dos meios de produção, que se configura o antagonismo entre classes sociais, 
assentado na chamada acumulação primitiva capitalista: "o processo histórico que dissocia o trabalhador dos meios de produção. É considerada primitiva porque constitui a pré-história do capital e do modo de produção capitalista" (MARX, 1980, p. 830).

Segundo Marx (1980), para a condição do assalariamento, primeiramente foi necessária a libertação da servidão e da coerção corporativa praticada na estrutura econômica feudal, extinguindo-se o feudalismo para a formação da estrutura econômica capitalista. Nessa transição histórica de sujeição ao feudalismo para a sujeição ao capitalismo, processou-se uma forma violenta de expropriação de grandes massas humanas dos seus meios de subsistência, como a expropriação da produção familiar, artesanal, camponesa, corporativa etc. Isso permitiu o surgimento do proletariado, uma população privada de seus meios de produção tendo que vender sua única mercadoria (a força de trabalho), formando-se, assim, uma volumosa reserva de mão de obra "livre" e disponível para ser comprada e explorada (MARX, 1980).

Desta feita, conforme afirma Ellen Wood (2011), o trabalho no mundo ocidental moderno assume uma posição histórica única e radicalmente diferente da sua história precedente. No centro da ideologia burguesa, a concepção de trabalho como "melhoramento", produtividade e qualidade inscreve-se na linguagem da economia moderna: mais aos capitalistas e menos aos trabalhadores, na qual os "produtores" do trabalho não são esses últimos, mas os primeiros. Ademais, sob essa ideologia, a esfera da produção subordina-se aos imperativos puramente "econômicos" do mercado e do lucro.

As relações sociais de propriedade consubstanciadas por essa ideologia burguesa colocaram o trabalho numa posição histórica única:

Submetido a imperativos econômicos que não dependem diretamente do status jurídico ou político, o trabalhador assalariado sem propriedade só pode desfrutar no capitalismo da liberdade e da igualdade jurídicas, e até mesmo de todos os direitos políticos de um sistema de sufrágio universal, desde que não retire do capital o seu poder de apropriação. É aqui que encontramos a maior diferença entre a condição do trabalho na antiga democracia ateniense e no capitalismo moderno. (WOOD, 2011, p. 172).

Com efeito, o produto do trabalho constitui valor de uso em qualquer forma social, mas, numa sociedade capitalista, o produto do trabalho é mercadoria. A mercadoria é o ponto de partida para entender a sociedade capitalista. Não à toa, Marx (2005), em sua obra O capital, dedica o primeiro capítulo para tratar da mercadoria, pois ela é a célula germinativa do modo de produção capitalista; a riqueza das sociedades capitalistas expressa-se como uma imensa coleção de mercadorias (MARX, 2005). Isso permite capturar que a sociedade burguesa é uma sociedade mercadorizada e feti- 
chizada. O fetiche da mercadoria encobre as desigualdades sociais das relações sociais capitalistas, tornando a realidade destituída da sua historicidade: as relações entre pessoas aparecem como relações entre coisas, relações alienadas (MARX, 2005).

A produção em geral está sob o signo da alienação. A religião, o direito, a família, o Estado, a moral, a ciência, a arte, entre outros, são apenas formas particulares de produção, afetadas, portanto, pela alienação em consequência da divisão do trabalho (MÉSZÁROS, 2016). Desse ponto de vista, o processo de alienação está no âmbito da produção e da reprodução social.

Assim, a alienação na teoria social de Marx tem um lugar central na explicação da realidade, capturada como processo inerente à relação capital-trabalho em quatro dimensões essenciais: em relação ao produto do trabalho, em relação à atividade vital, em relação ao seu ser genérico e em relação à socialidade. Quando as necessidades humanas são artificialmente produzidas pela racionalidade capitalista como necessidades de mercado, ocorre o processo de desumanização/alienação: a perda do sentido do ser genérico; "a perda da consciência dos vínculos com a natureza inerente ao ser humano" (MÉSZÁROS, 2016, p. 178), entendendose natureza humana como a capacidade de socialidade, de objetivar-se por meio do trabalho e do fazer história.

Isso posto, há que se considerar que as relações de gênero e raça estão inscritas nessas relações sociais desumanizadas. É no seio de uma sociabilidade burguesa racista patriarcal, na qual a engrenagem das relações é pela exploração-opressão, que é possível colocar-se em contato com a tematização identidades trans e cidadania.

A teoria social crítica permite entender o funcionamento e a legalidade da sociabilidade burguesa. Com a teoria feminista-marxista, é possível compreender que o patriarcado e o racismo também operam como determinação social na realidade junto com o capitalismo. Citando Saffioti (2000, p. 73): "foi, por conseguinte, o próprio Marx que me ensinou a pensar o nó, embora em sua época não the tenha sido possível fazê-lo. Aliás, o mais importante em um esquema de pensamento consiste no vigor de poder ensinar a pensar".

Ao contrário de uma concepção de patriarcado como sistema político e do capitalismo como sistema econômico, o que acaba por fracionar as dimensões política, social e econômica, fragmentando-se, portanto, o sistema dominação-exploração, Saffioti (2004) afirma que não há, de um lado, a dominação patriarcal e, de outro, a exploração capitalista, pois são duas faces de um mesmo modo de produzir e reproduzir a vida. Trata-se de uma ideologia que inscreve uma estrutura de poder e dominação masculina, subordinando o feminino e, por extensão, as identidades que irrompem as fronteiras de gênero. Em concordância com Saffioti (2013, p. 66): 
O modo capitalista de produção não faz apenas explicitar a natureza dos fatores que promovem a divisão da sociedade em classes sociais; lança mão da tradição para justificar a marginalização efetiva ou potencial de certos setores da população do sistema produtivo de bens e serviços. Assim é que o sexo, fator há muito selecionado como fonte de inferiorização social da mulher, passa a interferir de modo positivo para a atualização da sociedade competitiva, na constituição das classes sociais.

Estudos mais recentes da tradição feminista-marxista, como de Cínzia Arruzza (2015), evitando incorrer em reducionismos e economicismos, propõem uma teoria unitária para o debate das relações de opressãoexploração, na qual o patriarcado não é um sistema autonomizado do capitalismo e nem se subestima a centralidade da opressão de gênero.

Proponentes da 'teoria unitária' discordam da ideia de que o patriarcado seria hoje um sistema de regras e mecanismos que autonomamente se reproduzem. Ao mesmo tempo, insistem na necessidade de considerar o capitalismo não como um conjunto de leis puramente econômicas, mas antes como uma complexa e articulada ordem social, uma ordem que tem seu núcleo constituído de relações de exploração, dominação e alienação. (ARRUZZA, 2015, p. 38 - Grifos nossos).

A partir dessas contribuições feministas, este artigo refuta a afirmação de Ellen Wood (2011) sobre emancipação de gênero e raça como "bens extraeconômicos" - não obstante ela se constitua como uma importante marxista, que trouxe para o campo da produção teórica vigorosos debates entre democracia e atualidade do materialismo histórico. Não se trata, portanto, de desqualificar o lastro de pensamento da autora - uma vez que a desqualificação é uma estratégia colonial, e aqui não se pretende incorrer nessa reificação -, mas contestar o que ela desconsidera: que capitalismo, patriarcado e racismo se estruturam em simbiose. Vejamos o que afirma Wood (2011, p. 232):

Embora o capitalismo possa usar e faça uso ideológico e econômico da opressão de gênero, essa opressão não tem status privilegiado na estrutura do capitalismo. Ele poderia sobreviver à erradicação de todas as opressões específicas das mulheres, na condição de mulheres - embora não pudesse, por definição, sobreviver à erradicação da exploração de classe [...] não há necessidade estrutural específica de opressão de gênero no capitalismo, nem mesmo uma forte disposição sistêmica para ela.

Ao advogar que o capitalismo tão somente se utiliza das opressões de gênero, subsistindo a elas, ou ainda que ele não está estruturalmente vinculado a essas opressões, Wood (2011) não contribui para dar 


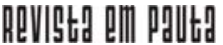

\} RELAÇÃO DE OPRESSÃO - MARINHO, S. \}

DOI: $10.12957 /$ rep.2021.56075

historicidade à realidade concreta. Sua exposição argumentativa separa a estrutura lógica do capital das suas dimensões históricas, incorrendo numa clássica confusão entre elas (ARRUZZA, 2015, p. 49-50). Assim, infere-se aqui que autonomizar a opressão de gênero e raça da exploração capitalista acaba por contribuir mais para se dicotomizar produção e reprodução e menos para tratá-las como unidade da totalidade das relações sociais, perdendo-se também a articulação dialética entre infraestrutura e superestrutura. Saffioti (1988), por sua vez, fala em termos de modo de produção capitalista e não em termos de lógica do capital justamente porque o modo de produção capitalista é o resultado histórico dessa simbiose e porque presume reprodução social.

É válido situar, portanto, a modernidade colonial e suas dimensões (gênero, raça, metrópole/colônia - norte/sul). O modo de produção capitalista na sua historicidade só se ergue e se consolida apoiado na estrutura patriarcal e racial do projeto colonizador no mundo-aldeia ${ }^{3}$, que transformou os referenciais de vida, cultura e trabalho das sociedades não capitalistas. Já é possível localizar uma série de estudos históricos que afirmam que o imperialismo e o colonialismo engendraram hierarquias de raça/ etnia e de gênero em sociedades onde os sistemas de gênero e raça desconheciam divisões hierárquicas ou existiam de forma não acentuada.

Rita Segato (2014), debruçando-se sobre a inter-relação existente entre colonialidade e patriarcado, lança luzes à existência de sistemas de gênero no mundo pré-intrusão e na modernidade colonial, inferindo que no mundo-aldeia existia uma organização patriarcal de baixa intensidade, que, transformada historicamente pelo gênero ocidental com o colonialismo, conformou-se no que chama de patriarcado colonial moderno, uma organização patriarcal de alta intensidade. Essa tese de Segato (2014) insere a categoria gênero como categoria central no desvelamento das dimensões da vida social totalizadas pela ordem colonial moderna.

É patente na história da formação capitalista a divisão entre civilizados e atrasados e entre os que têm direitos e os que não têm. A herança histórica da concepção moderna de direito formal abstrato, ao não considerar as desigualdades de status de cidadão, repõe na atualidade as desigualdades estruturais da sociedade moderna colonial.

Essa ótica contribui para a contextualização macro-histórica à análise da base material das relações sociais. O projeto colonizador no mundo-aldeia foi tão violento na transformação das formas de produzir e reproduzir a vida que passamos praticamente a considerar que a História da Humanidade começa com a cultura ocidental. A própria identidade trans que aqui se defende como identidade social politizada é, também,

\footnotetext{
${ }_{3}^{3}$ Aqui é utilizado o termo mundo-aldeia para um vocabulário descolonial, de modo a referir-se a um mundo não hierarquicamente organizado pela matriz da colonialidade. Para Rita Segato (2012), este mundo que antecedeu a intervenção colonial não deve ser descrito como pré-moderno, justamente para não sugerir que se encontra simplesmente no estágio anterior da modernidade e marcha inevitavelmente em direção a ela.
} 
produto histórico da colonialidade. As existências trans, mesmo anteriores à nossa sociedade moderna, são assim denominadas segundo a lógica do dominante/colonizador. Portanto, uma perspectiva de luta emancipatória e transformadora da condição de opressão-exploração deve estar vinculada também à descolonização do olhar, do saber e do existir para a superação da opressão colonial. E isso requer um exercício de desalienação.

Saffioti (1997) nos recorda que a realidade é móvel e que a alienação presume a desalienação, assim como a coisificação supõe a humanização. Uma reflexão baseada no próprio método marxista e, também, no papel que tem a ideologia: "graças à natureza porosa da ideologia e à emergência e ao desenvolvimento de contra-ideologias, as possibilidades de desalienação-humanização estão sempre presentes" (SAFFIOTI, 1997, p. 61). A referida autora chama a atenção para o fato de que o grau de reificação/alienação das pessoas nunca é total.

Inobstante o modo de produção capitalista, em simbiose com o patriarcado e o racismo, expressar-se como um sistema alienado de atividades humanas, não se pode ignorar, conforme Mészáros (2016, p. 189), que em tal sistema "são criadas também as condições para sua suplantação". As necessidades humanas não são somente necessidades de consumo e produção, "ideais também criam necessidades", portanto, "apenas da realização desses ideais pode-se esperar uma solução da contradição entre produção e consumo" (MÉSZÁROS, 2016, p. 190).

O fio condutor da análise da alienação em Marx é tomar como referência a interconexão entre seus aspectos econômicos, políticos, ontológicos, morais e estéticos, ante a sua equivocada consideração como determinações mecanicistas unilaterais, justamente para que a interpretação da realidade alcance a "clara luz do dia da análise social concreta" e torne possível um programa prático para sua reversão. Na empreitada da suplantação da alienação, exige-se uma mudança radical em todas as relações humanas, acabando com a causa - a produção de mercadorias - pois ela desumaniza toda atividade (MÉSZÁROS, 2016, p. 193).

\section{Algumas considerações sobre embates teórico-políticos: lutas gerais e lutas específicas e as relações entre a emancipação política e a emancipação humana}

Karl Marx (2009), em sua análise acerca da situação dos judeus na Alemanha no século XIX, privados dos direitos civis e políticos, elaborou o texto Para a questão judaica, oferecendo uma crítica ao liberalismo e refletindo sobre as relações existentes entre a emancipação política e a emancipação humana. O referido pensador alemão afirma que a questão da relação da emancipação política com a religião torna-se a questão da relação da emancipação política com a emancipação humana, trazendo 
elementos para compreender que reivindicar uma cidadania de Estado é apenas uma parte da contradição mundana universal entre o Estado político e a sociedade civil (MARX, 2009). Essa contradição não reside apenas naquelas pessoas que a reivindicam, mas na própria categoria da emancipação política.

Um refinamento dessa apreensão marxista pode ser localizado em Mészáros (2016, p. 119 - Grifos do autor), o qual define a política como "mediação (e, com suas instituições, como um meio dessa mediação) entre o estado presente e o estado futuro da sociedade". Portanto, a política, ainda que seja o caminho necessário para a prospecção de uma outra ordem societária, não alcança a suplantação da alienação, já que ainda se faz numa sociabilidade alienante.

Nesse sentido, é pela chave analítica da alienação em face do direito burguês à propriedade privada que Marx (2009) vai distinguir direitos humanos de direitos do cidadão. Afirma Marx (2009, p.63) que, sob a doutrina liberal, os chamados direitos do homem não são outra coisa senão os direitos do membro da sociedade civil burguesa e, portanto, "do homem egoísta, do homem separado do homem e da comunidade". Marx (2009, p. 64) vai criticar, também, o que consiste a liberdade no âmbito dos direitos humanos: "Mas, o direito humano à liberdade não se baseia na vinculação do homem com o homem, mas, antes, no isolamento do homem relativamente ao homem. É o direito desse isolamento, o direito do indivíduo limitado, limitado a si."

Conclui Marx (2009, p. 64) que a aplicação prática do direito humano à liberdade é um direito humano à propriedade privada (e o direito ao interesse próprio): "ela faz com que cada homem encontre no outro homem não a realização, mas antes a barreira da sua liberdade".

$\mathrm{Na}$ teia de hierarquias e desigualdades de poder de gênero, raça/ etnia e sexualidade não se pode perder de vista o conteúdo de classe, sob pena de se incorrer numa leitura e apreensão da realidade sem o prisma da totalidade. Quando não se utiliza a perspectiva do método materialista histórico-dialético na análise da vida social, por vezes, a trilha perseguida poderá nos conduzir às armadilhas da reificação. Um exemplo é o olhar conservador, próprio da ciência burguesa, que trata o ordenamento capitalista e, também, seus antagonismos de gênero e raça/etnia como naturais, embaçando, assim, a realidade.

Por outro lado, para a reflexão acerca da identidade de gênero como dimensão da cidadania faz-se necessário levantar uma discussão crítica em torno da repreensão às lutas chamadas específicas, como se existissem, tão somente, em detrimento das lutas gerais. Na tradição marxista, há muitas críticas ao que se denominou como "novos movimentos sociais", reconhecidos como movimentos culturais, sob a efervescência contestatória no plano da transformação da cultura, ao reivindicarem uma nova ordem das 
coisas, como os movimentos feministas, o movimento negro e o movimento LGBTQIA+.

A repreensão aos novos movimentos sociais é a de que são despolitizados para as questões de classe, pois só a luta de classes poderia superar a ordem vigente e construir uma nova ordem societária. É fato inconteste que muitas correntes do movimento LGBTQIA+ têm sua prática política dissociada da luta de classes, porém outras buscam uma caminhada de luta em articulação com as pautas classistas. É certo também que uma parcela significativa das lutas classistas reproduz o machismo, a misoginia, o racismo e a LGBTIfobia em sua práxis.

Desse modo, há que se concordar com Nancy Fraser (2002) - feminista estadunidense da teoria crítica - que, diante dessa nova gramática de reivindicação política, na qual se observa um descentramento da redistribuição (política de classe) para o reconhecimento (política cultural), é preciso examinar suas implicações para a justiça social. Uma dessas implicações, conforme Fraser (2002), é que o reconhecimento permite um alargamento da reivindicação política já não restrita ao eixo classe, dando atenção a outros eixos de subordinação (como raça/etnia, gênero, diferença sexual, sexualidade, idade, religião). Isso muda a paisagem da compreensão de justiça social, não mais cindida nas questões de redistribuição, mas abrangendo questões de representação, identidade e diferença. Isso é importante para a referida autora por estar na contramão dos paradigmas economicistas, dando-se a devida atenção para as hierarquias institucionalizadas de valor que não aquelas, tão somente, da economia política.

Por outro lado, tal dinâmica, segundo Fraser (2002), para efetivamente expressar um paradigma de justiça social mais amplo e rico, ou seja, que contemple as desigualdades de classe e as hierarquias de estatuto (raça/etnia, sexualidade, gênero, idade), não pode incorrer na substituição do paradigma truncado do economicismo para o paradigma truncado do culturalismo, sob pena de se incidir numa visão truncada de emancipação.

Para o risco da substituição da política de classe pela politização da cultura, Fraser (2002) propõe uma concepção bidimensional de justiça que abranja tanto o reconhecimento como a distribuição. A ideia é um olhar bifocal para justiça social: olhar tanto para uma política de redistribuição quanto para uma política de reconhecimento, já que nenhuma por si só basta.

Destarte, as pautas trans, feministas, de negras/os, LGBTQIA+ e de classe precisam andar juntas. Não há como hierarquizar as lutas. A pauta da luta de classes não deve se sobrepor à luta das questões de gênero, raça e sexualidade, e vice-versa. Logo, é falso hierarquizar e dizer que antes é preciso superar a dominação econômica para depois superar as demais. A dominação-exploração capitalista não é apenas econômica, é, também, política e cultural. As pautas em conjunto alargam a ideia de cidadania e democracia, afinal, numa sociedade capitalista-patriarcal-racista, a 
democracia é burguesa, patriarcal e branca, exigindo ser interpelada pelos sujeitos históricos e políticos.

Faz-se importante considerar, ainda, o conteúdo das lutas de pessoas trans como conteúdo político e, também, emancipatório. Na crítica à filosofia idealista hegeliana, Marx (2010) vai demonstrar que seu método é na práxis humana. A práxis é o fundamento da crítica à filosofia idealista. Marx (2010, p. 152 - Grifos do autor) criticava que a revolução alemã, para a filosofia idealista, estava "no cérebro do filósofo" alertando que: "[...] As revoluções precisam de um elemento passivo, de uma base material. A teoria só é efetivada num povo na medida em que é a efetivação de suas necessidades".

No tempo presente, há outras necessidades históricas que precisam ser analisadas, ainda que sobre as bases de uma estrutura de classes. Isso requer considerar que as categorias marxianas têm uma história e uma dinamicidade. A categoria classe social vem merecendo tratamento analítico e político que a sature de novas determinações, de modo a capturar sua complexidade, o que, naturalmente, também exige um novo olhar para os sujeitos políticos da ação transformadora da ordem vigente. O proletariado fabril como sujeito universal da luta emancipatória teve um tempo histórico. Essa ideia de um sujeito universal masculino não alcança a realidade concreta, ao contrário, a reifica.

\section{Considerações finais}

A ofensiva neoliberal contra a classe trabalhadora agudiza-se em momentos de crise do capital com a qual vivemos. O quadro atual do contexto brasileiro é ainda mais acentuado pelas constantes rupturas democráticas que se sucedem desde 2015, a partir do golpe civil político-parlamentar - com apoio jurídico e midiático - contra a Presidenta Dilma Rousseff (PT).

Seus efeitos mais expressivos são os constantes desmontes de direitos de cidadania arduamente conquistados, como as contrarreformas trabalhista (Lei Ordinária no 13467/2017) e previdência (PEC 133/2019), bem como a Emenda Constitucional no 95, aprovada em 2016, que congelou por vinte anos os gastos sociais, atingindo as condições de vida da classe trabalhadora. Diante desses ataques aos direitos sociais, são as pessoas trans, negras, mulheres, jovens e LGBTQIA+ os segmentos mais oprimidos, explorados e, sem dúvida alguma, os mais atingidos.

A atual crise do capital é acompanhada de projetos societários em disputa e, dentre eles, avançam o neoconservadorismo, os fundamentalismos, a intolerância, o obscurantismo, o anticientificismo e a violência, tornando mais ampliadas as expressões do machismo, da misoginia, do racismo, da homofobia/transfobia e do preconceito religioso. Não por acaso, 
o Brasil é o protagonista de um dado alarmante recentemente divulgado pela pesquisa da rede europeia Transgender Europe (TGEU): é o país que mais mata pessoas trans no mundo ${ }^{4}$.

Com efeito, a democracia burguesa tem, tão somente, a aparência de civilidade, que em momentos de crise acaba por assumir feições de barbárie. O cenário do poder político partidário brasileiro com as eleições de 2016 e com as últimas eleições de 2018 demonstra a aposta de uma parcela significativa da sociedade brasileira em candidatos/as afinados/as com a violência, o ódio, o autoritarismo, o discurso religioso da moral, dos costumes e da família tradicional, comprometendo a laicidade das ações do poder público e o respeito à diversidade identitária, que conforma a população brasileira. Ademais, as eleições evidenciaram um crescimento da extrema direita, que vem implementando um desavergonhado entreguismo ao capital internacional, golpeando, assim, as forças democráticas e de esquerda.

A conjuntura atual brasileira, portanto, é de derrocada de direitos já conquistados anteriormente, combinada à precária edificação de políticas e seu desmonte atual. Nessa conjuntura, ganha relevo a desseculizaração da política do tempo da Idade Média. Há evidências em diferentes espaços, desde as redes sociais às cadeiras do poder público, de impetuosos discursos morais e conservadores de ordem religiosa sobre gênero (normativo), sexualidade (heterossexual) e modelo (nuclear) de família, os quais vêm, sistematicamente, desqualificando outras existências e modos de ser.

Nesse caldo de cenários acachapantes, a partir de uma história de luta, as pessoas trans possibilitaram a visibilidade das suas contendas sociais na esfera pública. Por conseguinte, há que se concluir que o reconhecimento dos direitos de cidadania da população trans, ainda que saibamos que cidadania e democracia chocam-se com a lógica do capital, somente se torna possível com sua politização por meio da práxis humana. E, embora o alcance da emancipação humana que Marx acena seja possível somente numa sociedade sem classes, a emancipação política das pessoas trans é conditio sine qua non, é parte integrante da sua emancipação humana.

\footnotetext{
${ }^{4}$ Disponível em: https://nacoesunidas.org/violencia-contra-pessoas-trans-e-extremamente-alta-nas-americasapontam-onu-e-parceiros/. Acesso em: jul. 2019.
} 


\section{Referências}

ARRUZZA, C. Considerações sobre gênero: reabrindo o debate sobre patriarcado e/ou capitalismo. Outubro Revista, n. 23, 2015. Disponível em: http:/ /bit.ly/1IV8ss1. Acesso em: jan. 2019.

BENTO, B. Nome social para pessoas trans: cidadania precária e gambiarra legal. Revista Contemporânea, v. 4, n. 1, jan./jun. 2014. Disponível em: http://www.contemporanea.ufscar.br/index.php/contemporanea/article/ view/197.Acesso em: jan. 2019.

BENTO, B. A reinvenção do corpo: sexualidade e gênero na experiência transexual. Rio de Janeiro: Ed. Garamond, 2006.

CARVALHO, M. F. de L. Que mulher é essa? Identidade, política e saúde no movimento de travestis e transexuais. 2011. Dissertação (Mestrado em Saúde Coletiva) - Programa de Pós-Graduação em Saúde Coletiva, Uerj, 2011.

CASTEL, P. H. Algumas reflexões para estabelecer a cronologia do "fenômeno transexual" (1910-1995). Revista Brasileira de História, São Paulo, v. 21, n. 41, 2001.

COUTINHO, C. N. Notas sobre cidadania e modernidade. Praia Vermelha, Rio de Janeiro, v. 1, n. 1, set. 1997.

FRASER, N. A justiça social na globalização: redistribuição, reconhecimento e participação. Revista Crítica de Ciências Sociais, v. 62, out. 2002.

GRAMSCI, A. Problemas de filosofia e de história. In: GRAMSCI, A. Concepção dialética da história. Rio de Janeiro: Editora Civilização Brasileira, 1978.

KOSIK, K. Dialética do concreto. Rio de Janeiro: Paz e Terra, 1976.

MARINHO, S. Trajetórias em campo minado: juventudes trans e o mundo do trabalho. Dissertação (Mestrado em Serviço Social) - Programa de PósGraduação em Serviço Social, Uerj, 2017.

MARINHO, S. Diversidade de gênero na sociabilidade capitalista patriarcal: as identidades trans em perspectiva. Katálysis, Florianópolis, v. 21, n. 3, set./dez. 2018. Disponível em: https://periodicos.ufsc.br/index.php/katalysis/ article/view/1982-02592018v21n3p602/37975. Acesso em: jul. 2020.

MARX, K. A chamada acumulação primitiva. O capital. Livro 1, vol. 2. Rio de Janeiro: Civilização Brasileira, 1980.

MARX, K. Trabalho estranhado e propriedade privada. Manuscritos econômico-filosóficos. São Paulo: Boitempo, 2004.

MARX, K. A mercadoria. O capital. Livro I, vol. 1. Rio de Janeiro: Civilização Brasileira, 2005.

MARX, K. Para a questão judaica. São Paulo: Expressão Popular, 2009. 
MARX, K. Crítica da filosofia do direito de Hegel. São Paulo: Boitempo Editorial, 2010.

MARX, K.; ENGELS, F. Feuerbach e história. Rascunhos e anotações. In: MARX, K.; ENGELS, F. A ideologia alemã. São Paulo: Boitempo Editorial, 2007.

MÉSZÁROS, I. A teoria da alienação em Marx. São Paulo: Boitempo, 2016. RODOVALHO, A. M. O cis pelo trans. Estudos Feministas, Florianópolis, v. 25, n. 2, jan./abr. 2017.

SAFFIOTI, H. I. B. Movimentos sociais: a face feminina. In: CARVALHO, N. V. de (Org.). A condição feminina. São Paulo: Vértice, 1988.

SAFFIOTI, H. I. B. Violência de gênero: o lugar da práxis na construção da subjetividade. Lutas Sociais, São Paulo, v. 2, 1997.

SAFFIOTI, H. I. B. Quem tem medo dos esquemas patriarcais de pensamento? São Paulo: Boitempo, 2000.

SAFFIOTI, H. I. B. Gênero, patriarcado, violência. São Paulo: Perseu Abramo, 2004.

SAFFIOTI, H. I. B. A mulher na sociedade de classes. São Paulo: Expressão Popular, 2013.

SEGATO, R. L. Gênero e colonialidade: em busca de chaves de leitura e de um vocabulário estratégico descolonial. E-cadernos CES, v. 18, 2012. Disponível em: http://journals.openedition.org/eces/1533. Acesso em: jul. 2020.

SEGATO, R. L. Colonialidad y patriarcado moderno: expansion del frente statal, modernizacion, y la vida de las mujeres. In: MUNOZ, K.; CORREAL, D.; MIÑOSO, Y. Tejiendo de outro modo: feminismo, epistemología y apuestas descoloniales em Abya Yala. Colômbia: Editorial Universidad del Cauca, 2014.

TEIXEIRA, F. B. Vidas que desafiam corpos e sonhos: uma etnografia do construir-se no outro gênero e na sexualidade. Tese (Doutorado em Filosofia) - Instituto de Filosofia e Ciências Humanas, Universidade Estadual de Campinas, 2009.

WOOD, E. M. Democracia contra capitalismo: a renovação do materialismo histórico. São Paulo: Boitempo, 2011.

DOI: $10.12957 /$ rep.2021.56075

Recebido em 08 de março de 2020.

Aprovado para publicação em 10 de agosto de 2020.

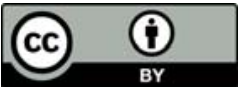

A Revista Em Pauta: Teoria Social e Realidade Contemporânea está licenciada com uma Licença Creative Commons Atribuição 4.0 Internacional. 